\title{
Unified mobile accessibility guidelines (UMAG)
}

\section{Directivas unificadas para la accesibilidad móvil (DUAM)}

\author{
LÓPEZ-GONZÁLEZ, Néstor Apolo†* \& GONZÁLEZ-BELTRÁN, Beatriz Adriana
}

Universidad Autónoma de México - Azcapotzalco

ID $1^{\text {st }}$ Author: Néstor Apolo, López-González / ORC ID: 0000-0002-9909-8575

ID $1^{\text {st }}$ Coauthor: Beatriz Adriana, González-Beltrán / ORC ID: 0000-0002-1718-9060

DOI: $10.35429 / J T P .2020 .17 .6 .10 .21$

Received January 25, 2020; Accepted April 01, 2020

\begin{abstract}
The attributes of a software product such as usability and accessibility are crucial, they allow the user to reach his/her goals, and additionally they give a better user experience. The first of them, usability, is oriented to satisfy the needs of the user with average capabilities and the second, accessibility is related to the users with disabilities. There is a lot of work published about web accessibility but, it is not the same case for mobile accessibility. This paper focuses on mobile accessibility guidelines, its overall aim consists of a set of unified mobile accessibility guidelines, based on guidelines such as Android, the British Broadcasting Corporation (BBC) and the World Wide Web Consortium (W3C). The method consisted of: Examine and organize the existent guidelines; find elements/components and properties/attributes related to them; verify if the guideline applies to the mobile environment then, unify guidelines if there are two or more of them. The result of this work consists of a set of unified guidelines to develop a mobile accessibility guidelines standard.
\end{abstract}

\begin{abstract}
Resumen
De entre los atributos de calidad de un producto de software se tienen a la usabilidad y la accesibilidad, ambos permiten a los usuarios la completitud exitosa de las tareas que realizan con el software no importando sus capacidades: La usabilidad enfocada al usuario con capacidades promedio y la accesibilidad orientada a los usuarios con discapacidad. Aunque existe gran variedad de trabajo desarrollado sobre la accesibilidad web, no es el mismo caso sobre la accesibilidad móvil. Este artículo se centra en las directivas de diseño para la accesibilidad móvil y su objetivo principal consiste en unificar las propuestas de directivas de Android, de la British Broadcasting Corporation (BBC) y del World Wide Web Consortium (W3C), esto como preámbulo para el desarrollo de un estándar específico sobre la accesibilidad móvil. El método utilizado para la unificación consistió en examinar y organizar las directivas de los autores mencionados; identificar elementos/componentes, así como propiedades/atributos que compartieran dichos conjuntos; verificar si la directiva tiene aplicación al ámbito móvil y proceder a unificarla si existen dos o más de ellas. El resultado es un conjunto de directivas de diseño para la accesibilidad móvil unificadas para dar pie al desarrollo de un estándar.
\end{abstract}

Directivas, accesibilidad, móvil

\footnotetext{
* Correspondence to Author (email: al2173804201@azc.uam.mx)

$\dagger$ Researcher contributing first author
} 


\section{Introduction}

The use of mobile devices (smartphones, tablets and smart watches, among others) is increasing (Anderson and Perrin, 2017), which implies that people must interact with mobile applications (apps) in order to do working and daily tasks. It is important to highlight that users have different extents of capabilities, on the one hand we have an average user, it means that user has the most people capabilities, but on the other hand we have disabled users (Lieberman, 2018), that is users with auditory, cognitive, learning, neurological, physical, speech and/or visual disabilities (W3C, 2017).

No matter the extent of users' capabilities, they must be able to operate and manipulate a mobile user interface. If we talk about average users, the accomplishment of the quality attribute of software named usability allows to reach that purpose, in case of disabled users, must be considered the quality attribute of software named accessibility.

The International Standardization Organization (ISO) has defined both quality attributes in 9241-11:2018 standard. Usability is defined such as "extent to which a system, product or service can be used by specified users to achieve specified goals with effectiveness, efficiency and satisfaction in a specified context of use", (ISO, 2018), and accessibility is defined such as "extent to which products, systems, services, environments and facilities can be used by people from a population with the widest range of user needs, characteristics and capabilities to achieve identified goals in identified contexts of use" (ISO, 2018).

It is important to remark that this paper focuses on mobile accessibility guidelines that support to developing mobile user interfaces operated and manipulated by disabled users, that is, unified guidelines that allows to implement the software quality attribute named accessibility on mobile apps.

In order to provide support to implement the accessibility attribute on mobile user interfaces, the World Wide Web Consortium (W3C), Android, the British Broadcasting Corporation (BBC), Apple, Blackberry, Microsoft, among others, have developed mobile accessibility guidelines.
It is important to say that a lot of work about web accessibility have been developed (Mariño and Pagnoni, 2020), but not for mobile accessibility. The ISO/IEC 40500:2012 standard is oriented to web accessibility. This standard is based on the Web Content Accessibility Guidelines (WCAG) developed by $\mathrm{W} 3 \mathrm{C}$ which can be adapted to the mobile environment.

At the present time there is not a specific standard to rule mobile accessibility. This paper focuses on the unification of the existent accessibility guidelines, in order to, in future works, to develop a mobile accessibility standard. The accessibility guidelines' proposers considered for this analysis were: $\mathrm{BBC}$ for the reason that it broadcasts to the world on radio, TV and online, offering news and information in 29 languages (BBC, 2019); The W3C because is a worldwide leader in web accessibility topics; and Android as it developed the most famous mobile operating system in the world (Android, n.d.).

The accessibility guidelines' proposers discarded were: Apple because the guidelines shown on its website focuses on assistive technology which is out of the reach of this work; BlackBerry as it were displaced by Android and Apple; and Windows Universal Platform (WUP) developed by Microsoft for the reason that its guidelines are oriented to a wide variety of devices such as mobile, personal computers, Xbox, HoloLens, Devices + IoT and surface hub (Microsoft, n.d.). Next are shown the sets of guidelines that were considered for the unification: BBC, Android and W3C (López and González, 2020). Also, the methodology used to unify the guidelines is described and finally, the unified mobile accessibility guidelines proposal is presented.

\section{BBC Mobile accessibility guidelines}

The guidelines developed by BBC are based on three principles: 1. Use platform and web standards as intended; 2. Use standard user interface controls where possible; and 3 . Support platform accessibility (BBC, 2017a). Guidelines are grouped in eleven issues: Audio and video, design, editorial, focus, forms, images, links, notifications, scripts and dynamic content, structure and text equivalents. (BBC, 2017b): 
First issue, audio and video includes the following recommendations: Provide subtitles, sign language, audio descriptions and transcriptions for embedded media (B1.1); and, audio must not play automatically, provide a pause/stop/mute button (B1.2), likewise, separate volume controls for background music, ambient sounds, narrative and editorially significant sound effects must be provided (B1.4). You have to keep in mind two considerations more: Relevant metadata for all media must be provided (B1.3) and narrative audio in games or interactive media should not conflict with native assistive technology (B1.5).

The design issue, groups the following suggestions: The color of text and background content must have sufficient contrast (B2.1); information or meaning must not be conveyed by color only (B2.2); core content must still be accessible when styling is unsupported or removed (B2.3); touch targets must be large enough to touch accurately, that is to say 7-10 $\mathrm{mm}$ (B2.4); an inactive space should be provided around actionable elements (B2.5); users must be able to control font sizing and user interface scaling (B2.6); links and other actionable elements must be clearly distinguishable (B2.7); when focused, all actionable and focusable elements must have a visible state change (B2.8); user's experience should be consistent (B2.9); interfaces must provide multiple ways to interact with content (B2.10); interactive media, including games, should be adjustable for user ability and preference (B2.11); lastly, content must not visibly or intentionally flicker or flash more than three times in any one-second period (B2.12). Regards to editorial issue, recommendations are: Consistent labelling should be used across websites and native applications (B3.1); the language of a page or app must be specified, and changes in language must be indicated (B3.2); ultimately, additional instructions should be provided to supplement visual and audio cues (B3.3). Guidelines about focus issue are: Only interactive elements must be focusable (B4.1); there must not be a keyboard trap (B4.2); content order must be logical (B4.3); actionable content must be navigable in a meaningful sequence (B4.4); actions must be triggered when appropriate for the type of user interaction (B4.5); and alternative input methods must be supported (B4.6).
Recommendations when you use forms are: All form controls must be labelled (B5.1); a default input format must be indicated and supported (B5.2); labels must be placed close to the relevant form control, and laid out appropriately (B5.3); form elements such as controls and labels must be properly grouped (B5.4); finally, focus or context must not automatically change during user input (B5.5).

About images issue, it is suggested that images of text should be avoided (B6.1). Equally important, must be considered that background images that convey information or meaning must have an additional accessible alternative (B6.2).

Links issue, consider the following suggestions: link and navigation text must uniquely describe the target or function of the link or item (B7.1); links to alternative formats must indicate that an alternative is opening (B7.2); and, repeated links to the same resource must be combined within a single link (B7.3).

Four guidelines has been developed for the notification issue: notifications must be both visible and audible (B8.1); standard operating system notifications should be used where available and appropriate (B8.2); lastly, clear error messages (B8.3) and non-critical feedback or assistance should be provided (B8.4).

The recommendations about scripts and dynamic content are: apps and websites must be built to work in a progressive manner that ensures a functional experience for all users (B9.1); media that updates or animated content must have a pause, stop or hide control (B9.2); automatic page refreshes must not be used without warning (B9.3); a timed response must be adjustable (B9.4); finally, interaction input control should be adaptable (B9.5).

Guidelines related to structure issue are: All pages or screens must be uniquely and clearly identifiable (B10.1); content must provide a logical and hierarchical heading structure (B10.2); containers should be used to describe page/screen structure (B10.3); and, controls, objects and grouped interface elements must be represented as a single accessible component (B10.4). 
Finally, suggestions concerning the text equivalents issue are next: Alternatives must briefly describe the editorial intent or purpose of the image, object, or element (B11.1); decorative images must be hidden from assistive technology (B11.2); tooltips must not repeat link text or other alternatives (B11.3); elements must have accessibility properties set appropriately (B11.4); and visual formatting alone must not be used to convey meaning (B11.5).

\section{Android Material Design: Accessibility}

Android provides a set of accessibility guidelines based on three principles: Clear, robust and specific. First principle consists in help users navigate by designing clear layouts with distinct calls to action. On the other hand, second principle is oriented to design the app to accommodate a variety of users. Finally, specific principle is focused on support assistive technologies specific to the platform, to support the input methods of touch, keyboard, and mouse (Android, n.d.).

Guidelines are organized in seven issues: Assistive technology, hierarchy, color and contrast, layout and typography, writing, sound and motion and implementing accessibility (Android, n.d.).

In respect of screen readers (A1.1) is suggested that the content must be labelled in order to TalkBack can read a text-only version correctly (A1.1.1), it means you have to make sure that the app can work with screen readers (A1.1.2). The interface can be explored by touch that is to allow users to run their finger over the screen to hear what is directly underneath or by linear navigation that is to say backwards or forwards on screen to read pages linearly, from top to bottom (A1.1.3). When directional controllers are used, they should to allow users to jump from selection to selection in a linear fashion (A1.2.1).

In regard to hierarchy (A2.1), is suggested: Clearly visible elements (A2.1.1), sufficient contrast and size (A2.1.2), a clear hierarchy of importance (A2.1.3) and key information that is discernable at a glance (A2.1.4).
Additionally, you should consider placing important actions at the top or bottom of the screen, reachable with shortcuts (A2.1.5) and related items of a similar hierarchy next to each other (A2.1.6). Also, it is relevant: that users knows where they are in the app and what is important (A2.1.7); provide visual and touch feedback (A2.1.8); visual feedback (labels, colors and icons) and touch feedback show users what is available in the UI (A2.1.9); and use multiple visual and textual cues like color, shape, text, and motion to emphasize which information is important (A2.1.10).

About focus (A2.2) is recommended that: Input focus flows from the top to the bottom of the screen (A2.2.1); it can traverse from the most important to the least important item (A2.2.2); determine your focus points and movements, considering the order in which elements receive focus, the way in which elements are grouped and where focus moves when the element in focus disappears (A2.2.3); focus location must be clear, you can use visual indicators and accessible text for that purpose (A2.2.4); focus control, when keyboard is used or the user reads the content, can be implemented for frequently used tasks (A2.2.5); navigation should have a clear flow, it means, task can be done in a few steps (A2.2.6); finally, navigation controls must be easy to locate and clearly written.

Related to grouping (A2.3), is suggested that items can be grouped using headings that communicate what the groupings are. These groups organize content spatially (A.3.2.1).

There are two guidelines about transitions (A2.4): Transversal focus between screens and task must be continuous (A2.4.1); and focus should locate on the element that was previously focused when a task is interrupted and then resumed (A2.4.2). 
Also, guidelines indicate that should be used color (A3.1) and contrast (A3.2) to help users see and interpret the content of the app, interact with elements and understand actions (A3.3.1). Additionally, is recommended: use primary, secondary and accent colors (A3.3.2); provide sufficient color and contrast between elements to see and use the app (A3.3.3); contrast ratio between a color and its background ranges from 1-21 based on its luminance (A3.2.1.); finally, the higher the difference between the two numbers in the ratio, the greater the difference in relative luminance between the colors (A3.2.2).

On the other hand it is recommended: logos and decorative elements with an important function must be distinguishable (A3.3.1); for users who are colorblind, or cannot see differences in color, other design elements can help express the same amount of information (A3.4.1); multiple visual cues help communicate important states (A3.4.2); and elements such as strokes, indicators, patterns, texture, or text can describe actions and content (A3.4.3).

An important issue to consider are touch targets which should be at least 48 x $48 \mathrm{dp}$, it means size of about $9 \mathrm{~mm}$, regardless of screen size (A4.4.1). The recommended target size for touchscreen elements is 7-10 $\mathrm{mm}$ (A4.1.2). In respect of pointer targets, they should be at least 44 x $44 \mathrm{dp}$ and they should be separated by $8 \mathrm{dp}$ of space or more (A4.1.3).

In order to increase the accessibility of design (A4.2), it must be considered to use flexible and responsive designs (A4.2.1). About related items, they can be grouped in proximity to one another (A4.2.2).

Typography issue includes guidelines about accessibility text (A5.1), elements with state changes (A5.2) and hint speech (A5.3). First, visible and nonvisible alternative text must be descriptive and meaningful (A5.1.1) as well as, clear, short and succinct (A5.1.2). Screen readers must be able to announce a control's type or state (A5.1.3).
Also, it is recommended; use action verbs to indicate what an element or link does if tapped, rather than what an element looks like (A5.1.4); links text should specify what will occur if an action or link is selected (A5.1.5); ultimately, make sure that an element has the same description no matter the page it is located (A5.1.6).

Secondly, when elements with state changes (A5.2) are used, it is suggested: announce the icons according to how it is presented to the user (A5.2.1); if the icon is a property of an item, screen readers will verbalize the current state (A5.2.2); if the icon is an action, if the icon is selected, the text label can specify the action that occurs (A5.2.3); and, the users may be navigating with a keyboard, fingers or mouse, so keep that in mind when telling them how to interact with a control (A5.2.4).

Thirdly, about hint speech (A5.3), is suggested to use it moderately and in case of complex user graphic interfaces (A5.3.1).

Next issue, sound (A6.1) and motion (A6.2), includes guidelines that suggest: provide visual alternatives such as closed captions or transcriptions (A6.1.1); users can navigate across app using sound when descriptive labels to UI elements have been added (A6.1.2); avoid sounds that interfere with screen readers, you should provide controls for users to pause or stop sounds (A6.1.3); lastly, avoid extra sound added to native elements (A6.1.4).

About motion issue, you should consider what W3C says: Enable content that moves, scrolls, or blinks automatically to be paused, stopped, or hidden if it lasts more than five seconds (A6.2.1); limit flashing content to three times in a one-second period to meet flash and red flash thresholds (A6.2.2); and avoid flashing large central regions of the screen (A6.2.3).

Sound and motion recommendations include two guidelines about timed controls, first avoid timers when controls that perform high-priority functions are provided (A6.3.1) and second, controls that enable important functions can allow users to turn them on again, or perform the same function in other ways (A6.3.2).

LÓPEZ-GONZÁLEZ, Néstor Apolo \& GONZÁLEZBELTRÁN, Beatriz Adriana. Unified mobile accessibility guidelines (UMAG). Journal of Technological Prototypes. 2020 
Finally, relating to implementing accessibility (A7.1) is important to consider meeting each platform's accessibility standards and supporting its assistive technology (A7.1.1). Documentation (A7.2) must be included, it entails that features with special accessibility considerations can be included in help documentation (A7.2.1), additionally, it must be relevant, accessible and visible (A7.2.2).

Regarding to testing and research (A7.3) is suggested: Test the app with various assistive technologies turned on (A7.3.1); have users with impairments test your app (A7.3.2); consider how individual elements can be made more accessible while also fitting together in a coherent user flow (A7.3.3); make the major tasks as usable as possible for a wide range of users (A7.3.4); finally, learn about user's needs and what they want out of the app (A7.3.5).

\section{Web Content Accessibility Guidelines (WCAG 2.0)}

The guidelines proposed by World Wide Web Consortium (W3C) are grouped into four principles: Perceivable, operable, understandable and predictable. The guidelines that are part of each principle are shown below (W3C, 2008).

To begin, the perceivable principle includes guidelines about text alternatives, which must be provided and allow the user to change them into other forms such as large print, braille, speech, symbols or simpler language for any non-text content (W1.1). Also, it is important to highlight that any content that is not a sequence of characters, must have a text alternative (W1.1.1).
In regard to time based media (W1.2), it is important to provide: Equivalent information for audio that is not live and/or an audio track that presents equivalent information for video that is not live (W1.2.1); captions for all prerecorded audio content (W1.2.2); an audio description or an alternative for time-based media of the prerecorded video (W1.2.3); captions for all live audio content (W1.2.4); audio description for all prerecorded video content (W1.2.5); sign language interpretation for all prerecorded audio content (W1.2.6); an extended audio description for all prerecorded video content where pauses in foreground audio are not sufficient to allow audio descriptions to convey the sense of the video (W1.2.7); an alternative for time-based media for all prerecorded synchronized media and for all prerecorded video-only media (W1.2.8); and an alternative for time-based media that presents equivalent information for live audio-only (W1.2.9).

Guidelines about adaptable issue, that consist of create content that can be presented in different ways without losing information or structure (W1.3), suggest that: Information, structure, relationships and a correct reading sequence can be determined by software (W1.3.1, W3.1.2); instructions provided to understand and operate content, include more than just sensory characteristics of components such as shape, size, visual location, orientation, or sound (W1.3.3).

In respect of distinguishable issue, it is important to point out use more than color to conveying information, indicating an action, prompting a response, or distinguishing a visual element (W1.4.1). Also, must be provided a mechanism to pause or stop automatically played audio, as well as a mechanism to control audio volume (W1.4.2).

About text and images of text, it is important to highlight that they must have a contrast ratio of at least 4.5:1 (W1.4.3). In addition, text can be resized without assistive technology up to $200 \%$ without loss of content or functionality (W1.4.4) and does not requiring horizontal scrolling. 
Also, must be considered that: text be used to convey information rather than images of text (W1.4.5); the visual presentation of text and images of text has a contrast ratio of at least 7:1 (W1.4.6); and the user can select the foreground and background colors of the block of text.

Moreover, the width of the block of text is no more than 80 characters or glyphs (40 if Chinese, Japanese or Korean) and text must be not justified. Additionally, line spacing is at least space-and-a-half within paragraphs and paragraph spacing is at least 1.5 times larger than the line spacing (W1.4.8). Finally, images of text are only used for pure decoration or where a specific presentation of text is essential to convey information (W1.4.9). On the other hand, prerecorded audio-only content that contains speech must not to contain background sounds, on the contrary, background sounds must be at least 20 decibels lower than the foreground speech content and they can be turned off (W1.4.7).

Second principle, operable, groups guidelines about how the user interface components and navigation become operable, it means make available all functionality from a keyboard (W2.1). Additionally, the functionality of content must be operable through a keyboard interface without requiring specific timings for individual keystrokes (W2.1.1, 2.1.3). Also, the keyboard trap does not occur (W2.1.2). It is strongly recommended to provide users enough time to read and use content (W2.2) and that user will be able to turn off, adjust and extend, at least 20 seconds, the time limit (W2.2.1). Moreover, the timing is not an essential part of the event or activity presented by the content (W2.2.3).

It is suggested that for any moving, blinking, scrolling and auto-updating there is a mechanism for the user to pause, stop, or hide it. About auto-updating is important to provide a mechanism for the user to control the frequency of the auto-updates (W2.2.2). In case of an interruption occurs, it can be postponed or suppressed by the user (W2.2.4). Finally, if an authenticated session expires, the user can continue the activity without loss of data after re-authenticating (W2.2.5).
About seizures (W2.3), it is suggested that web pages do not contain anything that flashes more than three times in any one second period, or the flash is below the general flash and red flash thresholds (W2.3.1, W2.3.2).

About navigable issue, that means to provide ways to help users navigate, find content, and determine where they are (W2.4), it is recommended to include a mechanism to bypass blocks of content that are repeated on multiple Web pages (W2.4.1), as well as titles (W2.4.2), headings that be used to organize content (W2.4.10), and labels that describe topic or purpose (W2.4.6). Additionally, multiple ways are available to locate a Web page (W2.4.5) as well as information about the user's location within a set of Web pages (W2.4.8). Moreover, navigable issue includes guidelines about focus and links too. First, the focusable components receive focus in an order that preserves meaning and operability (W2.4.3); secondly, the keyboard focus indicator is always visible (W2.4.7). Finally, it is important to highlight that the purpose of each link can be determined from the link text alone (W2.4.9) or from the link text together with its programmatically determined link context (W2.4.4).

Third principle means that the information and the operation of user interface must be understandable. The understandable principle groups guidelines about readable issue, which suggests that the default human language of each Web page and the human language of each passage or phrase in the content can be determined by software (3.1.1 and 3.1.2). It is necessary that a Web page includes a mechanism for identifying: Specific definitions of words or phrases used in an unusual or restricted way, including idioms and jargon (3.1.3); the expanded form or meaning of abbreviations (3.1.4); specific pronunciation of words where meaning of the words, in context, is ambiguous without knowing the pronunciation (3.1.6) and is available a version that does not require reading ability more advanced than the lower secondary education level (3.1.5).

Guidelines related to predictable issue, that means make Web pages appear and operate in predictable ways (W3.2), suggest about changes of context that: 
They are initiated only by user request or a mechanism is available to turn off such changes (W3.2.5), and they are not initialized when a component receives the focus (W3.2.1) or when is changed the setting of any user interface component (W3.2.2).

Additionally, the components that have the same functionality within a set of Web pages must be identified consistently (W3.2.4). Finally, navigational mechanisms that are repeated on multiple Web pages occur in the same order each time they are repeated (W3.2.3).

Input assistance issue, that refers to help users avoid and correct mistakes, includes suggestions about provide labels or instructions when content requires user input (W3.3.2) in addition to provide contextualized help (W3.3.5). If an input error occurs, it must be automatically detected, as well as the item that is in error, and described to the user in text (W3.3.1), providing suggestions to correct it (W3.3.3).

Web pages that cause legal commitments or financial transactions, that modify or delete user-controllable data in data storage systems or that submit user test responses, it is important to allow reversible submissions. Data entered by users must be checked for input errors and must be provided an opportunity to correct them. A mechanism is available for reviewing, confirming, and correcting information before finalizing the submission (W3.3.4, W3.3.6). The fourth principle, robust refers to the content must be robust enough that it can be interpreted reliably by a wide variety of user agents, including assistive technologies. Guidelines included in this principle pretend to maximize compatibility with current and future user agents, including assistive technologies (W4.1). Moreover, guidelines suggest use the markup languages correctly (W4.1.1) and programmatically set, for all user interface components, names, roles, states, properties and values; changes to these items are available to user agents, including assistive technologies.

\section{Methodology}

The methodology used to unify guidelines is shown in Figure 1. It is comprised of next steps:
1. We must identify the element/component that guideline refers to, that is, if guideline is related to audio, font, video, links, among others.

2. Now, we need to identify the property /attribute related to guideline previously selected in step 1. For example, audio has the next properties/attributes: playing, stopping, volume control, pausing, and closed captioning, among others.

3. Once identified the information referred in step 1 and 2, it is time to search the guidelines in each set. The guidelines selected must have related to the element/component and property/attribute identified.

4. We have to verify that selected guideline can be directly implemented on mobile environment, conversely, we have to verify that it can be adapted to the mobile environment. Both cases, the guideline will be considered for the unification process.

5. If there are two or more guidelines, they will be unified, on the contrary, the guideline will be considered as its original form.

6. As a result, we have a unified guideline. 


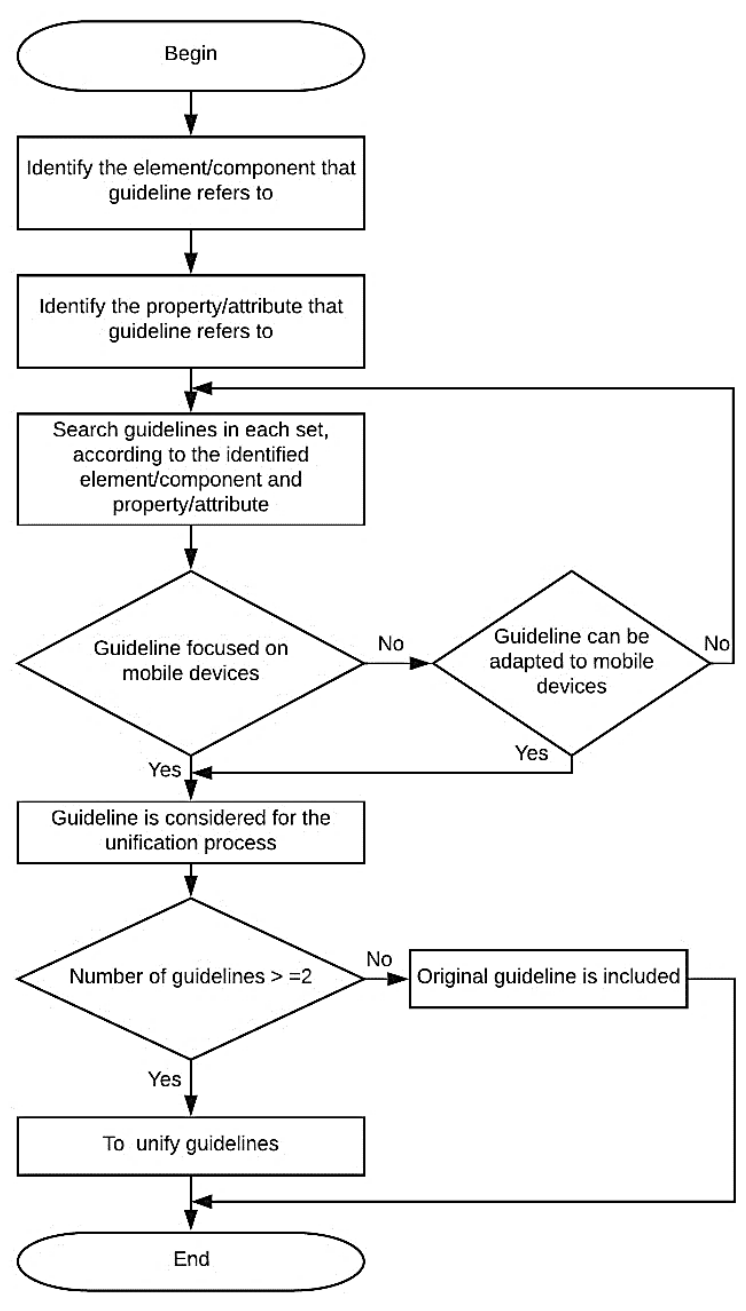

Figure 1 Methodology for unifying mobile accessibility guidelines

Source: own elaboration

\section{Results}

As a result, unified accessibility guidelines are shown in table 1 , which are categorized in 21 topics: 1. Focus, 2. Links, 3. Audio, 4. Video, 5. Text, 6. Color, 7. Contrast, 8. Data input, 9. Assistive technology, 10. Notifications, 11. Labels, 12. Structure, 13. Navigation, 14. Behavior/Functionality, 15. Actionable elements, 16. Errors, 17. Instructions, 18. Help, 19. Keyboard, 20. Temporizers and 21. Image. The organization of the guidelines was made in order to provide an easy identification and reading when they are implemented by the designer or programmer. Also, in Table 1 you will find two columns: reference and guideline. The column called reference shows the identifiers of the guidelines that originate the new unified guidelines. The code used to identify each guideline is comprised of two elements: a capital letter related to the name of the proposer (BBC, Android or W3C) and the number of the guideline. The second column contents the unified accessibility guidelines, which are shown below.

\begin{tabular}{|c|c|}
\hline $\begin{array}{l}\text { 1. Focus } \\
\text { Reference }\end{array}$ & Guideline \\
\hline $\begin{array}{l}\text { B2.8 } \\
\text { B4.1 } \\
\text { A2.2.4 } \\
\text { W2.4.7 } \\
\text { W3.2.1 }\end{array}$ & $\begin{array}{l}\text { The focus must be, all the time, visible and } \\
\text { easily identifiable, it means that user can } \\
\text { know where the focus is located. In order to } \\
\text { achieve this goal, it is recommended to } \\
\text { include visual indicators and accessible text. } \\
\text { It is important to consider that a change of } \\
\text { context must not be initialized when a } \\
\text { component receives the focus. }\end{array}$ \\
\hline $\begin{array}{l}\text { B4.3 } \\
\text { B4.4 } \\
\text { A2.2.1 } \\
\text { A2.2.2 } \\
\text { A2.2.3 } \\
\text { W2.4.3 }\end{array}$ & $\begin{array}{l}\text { When focus navigation is defined, it is } \\
\text { important to consider that: } \\
\text { - The sequence of the focus must be useful } \\
\text { for the user. } \\
\text { - Preferably from top to bottom. } \\
\text { - From the most to the least important } \\
\text { element. } \\
\text { - Match the focus navigation with the order } \\
\text { of the content. }\end{array}$ \\
\hline $\begin{array}{l}\text { A2.4.1 } \\
\text { A2.4.2 }\end{array}$ & $\begin{array}{l}\text { The focus navigation must not be } \\
\text { interrupted, it means, must be continuous. } \\
\text { When a task is interrupted, and later is } \\
\text { restarted, the focus must be situated where } \\
\text { it was located before the interruption. }\end{array}$ \\
\hline \multicolumn{2}{|r|}{ е } \\
\hline Reference & Guideline \\
\hline $\begin{array}{l}\text { B2.7 } \\
\text { B7.1 } \\
\text { B7.2 } \\
\text { B7.3 } \\
\text { B11.3 } \\
\text { A5.1.4 } \\
\text { A5.1.5 } \\
\text { W2.4.4 } \\
\text { W2.4.9 }\end{array}$ & $\begin{array}{l}\text { The links must be distinguishable for users. } \\
\text { It is recommended: } \\
\text { - The text of the link must show its } \\
\text { purpose, it means, the consequence of being } \\
\text { selected. } \\
\text { - If a link addresses to an alternative } \\
\text { version, then it must be indicated. } \\
\text { - If different links address to the same } \\
\text { resource, then they must be blended. } \\
\text { - The screen readers must not read the text } \\
\text { of the link. } \\
\text { - The text of the link must be succinct. }\end{array}$ \\
\hline \multicolumn{2}{|r|}{ 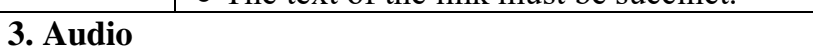 } \\
\hline Reference & Guideline \\
\hline $\begin{array}{l}\text { B1.1 } \\
\text { B1.2 } \\
\text { B1.3 } \\
\text { B1.4 } \\
\text { B1.5 } \\
\text { A6.1.3 } \\
\text { A6.1.4 }\end{array}$ & $\begin{array}{l}\text { When audio is being incorporated, it is } \\
\text { suggested: } \\
\text { - Include alternative content such as closed } \\
\text { captions, sign language, descriptions and } \\
\text { transcriptions. } \\
\text { - Avoid auto playing. } \\
\text { - Provide stop, pause, close, volume and } \\
\text { play controls. } \\
\text { - Must not be included extra sounds. In } \\
\text { case of being included, they must not } \\
\text { conflict with assistive technology. } \\
\text { - Background sounds must be } 20 \text { decibels } \\
\text { lower than the foreground sounds. }\end{array}$ \\
\hline \multicolumn{2}{|r|}{ 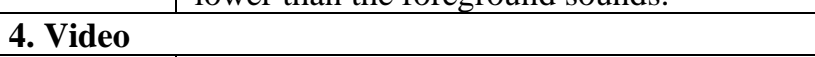 } \\
\hline Reference & Guideline \\
\hline $\begin{array}{l}\text { B1.1 } \\
\text { B1.2 } \\
\text { B1.3 } \\
\text { B1.4 } \\
\text { W1.1 } \\
\text { W1.4 }\end{array}$ & $\begin{array}{l}\text { When video is being incorporated, it is } \\
\text { recommended: } \\
\text { - Include alternative content such as closed } \\
\text { captions, sign language, descriptions and } \\
\text { transcriptions. } \\
\text { - Avoid auto playing. } \\
\text { - Provide stop, pause, close, volume and } \\
\text { play controls. }\end{array}$ \\
\hline
\end{tabular}
guidelines (UMAG). Journal of Technological Prototypes. 2020 


\begin{tabular}{|c|c|}
\hline \multicolumn{2}{|l|}{ 5. Text } \\
\hline Reference & Guideline \\
\hline $\begin{array}{l}\text { B2.6 } \\
\text { A4.3.1 } \\
\text { A4.3.2 } \\
\text { A4.3.3 } \\
\text { A5.1.1 } \\
\text { A5.1.2 } \\
\text { W1.4 } \\
\text { W1.4.8 }\end{array}$ & $\begin{array}{l}\text { When text is being shown, it is } \\
\text { recommended to consider: } \\
\text { - The text must be descriptive, meaningful, } \\
\text { succinct and distinguishable. } \\
\text { - Text alignment must not be justified. Line } \\
\text { spacing must be at least } 1.5 \text { lines. } \\
\text { - Must be used scalable pixels (sp). } \\
\text { - Text must be compatible with assistive } \\
\text { technology. } \\
\text { - The letter spacing must be enough in case } \\
\text { of letter size be increased by user or the } \\
\text { block of text includes CJK (Chinese, } \\
\text { Japanese and Korean) characters or others. } \\
\text { - The font size must be customizable. }\end{array}$ \\
\hline \multicolumn{2}{|r|}{ - } \\
\hline Reference & Guideline \\
\hline $\begin{array}{l}\text { B2.2 } \\
\text { B11.5 } \\
\text { A3.1.1 } \\
\text { A3.1.2 } \\
\text { A3.1.3 } \\
\text { W1.4.1 } \\
\text { W1.4.8 }\end{array}$ & $\begin{array}{l}\text { When colors are shown, it is recommended: } \\
\text { - Use primary, secondary and accent } \\
\text { colors. } \\
\text { - The background and foreground colors } \\
\text { must be customizable by user. } \\
\text { - Do not use only color to convey } \\
\text { information, meaning or request a response. }\end{array}$ \\
\hline \multicolumn{2}{|c|}{ 7. Contrast } \\
\hline Reference & Guideline \\
\hline $\begin{array}{l}\text { B2.1 } \\
\text { A3.1.1 } \\
\text { A3.1.3 } \\
\text { W1.4.3 } \\
\text { W1.4.6 }\end{array}$ & $\begin{array}{l}\text { The contrast ratio (minimum) between text } \\
\text { and images must be, at least } 4.5: 1 \text {. When } \\
\text { contrast increases ratio must be } 7: 1 \text {. } \\
\text { The color of the text and background must } \\
\text { have enough contrast in order to ease the } \\
\text { reading, interacting and interpretation of the } \\
\text { content. }\end{array}$ \\
\hline \multicolumn{2}{|c|}{ 8. Data input } \\
\hline Reference & Guideline \\
\hline $\begin{array}{l}\text { B4.6 } \\
\text { B5.2 } \\
\text { B9.5 } \\
\text { W3.2.2 } \\
\text { W3.3 } \\
\text { W3.3.1 }\end{array}$ & $\begin{array}{l}\text { About data input, is suggested: } \\
\text { - Provide a variety of data input methods. } \\
\text { - A default format data input must be } \\
\text { provided. } \\
\text { - When a user interacts with a control, it } \\
\text { must be adaptable. } \\
\text { - Help the user to avoid and correct errors. } \\
\text { When errors are detected, it must be } \\
\text { identified, and text described to user. }\end{array}$ \\
\hline \multicolumn{2}{|c|}{ 9. Assistive technology } \\
\hline Reference & Guideline \\
\hline $\begin{array}{l}\text { B1.5 } \\
\text { A1.1.1 } \\
\text { A1.1.2 } \\
\text { A1.1.3 } \\
\text { A1.1.7 } \\
\text { A7.1.1 } \\
\text { W4.1 }\end{array}$ & $\begin{array}{l}\text { The content or the elements of the graphic } \\
\text { user interface must not interfere with } \\
\text { assistive technologies. The compatibility } \\
\text { with assistive technologies must be } \\
\text { maximized. } \\
\text { In case of a screen reader is used, the } \\
\text { content must be properly labeled. } \\
\text { The text read by screen readers must be } \\
\text { meaningful and helpful. } \\
\text { Accessibility and assistive technology } \\
\text { standards must be considered. }\end{array}$ \\
\hline \multicolumn{2}{|c|}{ 10. Notifications } \\
\hline Reference & Guideline \\
\hline $\begin{array}{l}\text { B8.1 } \\
\text { B8.2 }\end{array}$ & $\begin{array}{l}\text { Regarding to notifications, is suggested: } \\
\text { - They must be visuals and audible } \\
\text { - Operating System standard notifications } \\
\text { must be used where they are available and } \\
\text { appropriated. }\end{array}$ \\
\hline
\end{tabular}

ECORFAN® Todos los derechos reservados

\begin{tabular}{|l|l|}
\hline 11. Labels \\
\hline Reference & Guideline \\
\hline B3.1 & The controls displayed in the form must be \\
B5.1 & correctly labeled. Labels must be close to \\
B5.3 & the control. \\
B5.4 & Labeling must be consistent. Labels must be \\
W3.3.2 & correctly grouped. \\
& Labels must be included when user data \\
& input is needed. \\
\hline
\end{tabular}

\section{Structure}

Reference Guideline

B10.2 $\quad$ The content must be logically structured,

B4.3 with a clear hierarchy and a correct reading

A2.3.1 sequence.

W1.3.2 The pages and forms must be easily and B10.1 uniquely identifiable. It is recommended to

B10.3 use headers and titles that describe the topic A2.1.1 or purpose.

W2.4.10 The most important actions must be located

W2.4.6 on the top of the screen meanwhile the least A2.1.5 on the bottom.

A2.1.4 The key information must be identifiable at A2.1.6 a glance.

W2.4.1 Group elements with a similar hierarchy

\section{Navigation}

Reference $\quad$ Guideline

\begin{tabular}{l|l} 
A2.1.7 & Help the user to know where he is located
\end{tabular}

A2.1.8 within app.

A5.1.6 When a mechanism is used in different

W2.4.8 pages or locations, it must work, be

W2.4 displayed and described in the same way.

W3.2.3

\section{Behaviour/functionality}

\section{Reference Guideline}

B 9.1 $\quad$ Auto-updating must not initialize without a

B.9.2 prior notice. Controls must be provided to

B.9.3

A5.2.3 The elements are shown in the way that

A5.2.5 they are used.

W3.2 The software must work in a progressive and predictable way for all users.

\section{Accionable elements}

Reference Guideline

B2.4 $\quad$ Actionable elements must be clearly

B2.5 distinguishable; an inactive space must be

B2.7 included surround them.

A4.1.1 Actionable elements must have enough size A4.1.2 in order to interact with them, it means $48 \mathrm{x}$ A4.1.3 $48 \mathrm{dpi}$ or $9 \times 9 \mathrm{~mm}$. Also, they must be between 7 and $10 \mathrm{~mm}$ in size.

Point targets must be $44 \times 44 \mathrm{dp}$.

\section{Errors}

Reference Guideline

W3.3.1 If an error is automatically detected then the

W3.3.3 failing element must be identified, and the

W3.3.4 error must be described in text. Also, help

B8.3 must be provided in order to avoid and correct the errors.

The error and correction messages must be clear.

It is important to consider:

- Information submission can be cancelled.

- Mechanisms must be provided to verify, confirm and correct information before submitting. 


\begin{tabular}{|c|c|}
\hline \multicolumn{2}{|c|}{ 17. Instructions } \\
\hline Reference & Guideline \\
\hline $\begin{array}{l}\text { B3.3 } \\
\text { W3.3.2 }\end{array}$ & $\begin{array}{l}\text { Provide additional instructions when visual } \\
\text { and audio complements are included. } \\
\text { Labels and instructions are provided when } \\
\text { the content require user data entry. } \\
\text { Instructions must be succinct. }\end{array}$ \\
\hline \multicolumn{2}{|l|}{ 18. Help } \\
\hline Reference & Guideline \\
\hline $\begin{array}{l}\text { B8.4 } \\
\text { A2.1.7 } \\
\text { A2.1.8 } \\
\text { A2.1.9 } \\
\text { A7.2.1 } \\
\text { A7.2.2 } \\
\text { W3.3.1 } \\
\end{array}$ & $\begin{array}{l}\text { Help or/and feedback must be provided, } \\
\text { which can be visual and tactile. } \\
\text { Help must be provided to avoid and correct } \\
\text { errors. } \\
\text { Help documentation must be accessible and } \\
\text { relevant. }\end{array}$ \\
\hline \multicolumn{2}{|c|}{ 19. Keyboard } \\
\hline Reference & Guideline \\
\hline $\begin{array}{l}\text { B4.2 } \\
\text { W2.1.1 } \\
\text { W2.1.2 } \\
\text { W2.1.3 }\end{array}$ & $\begin{array}{l}\text { Keyboard trap must be avoided. } \\
\text { All the functionality must be available using } \\
\text { the keyboard. No timing. }\end{array}$ \\
\hline \multicolumn{2}{|c|}{ 20. Temporizers } \\
\hline Reference & Guideline \\
\hline $\begin{array}{l}\text { B9.4 } \\
\text { A6.3.1 } \\
\text { A6.3.2 } \\
\text { W1.2 } \\
\text { W2.1.1 } \\
\text { W2.1.3 } \\
\text { W2.2 } \\
\text { W2.2.1 } \\
\text { W2.2.3 }\end{array}$ & $\begin{array}{l}\text { Temporizers must be avoided when high } \\
\text { priority functions are included. Conversely, } \\
\text { the user will be able to control, deactivate, } \\
\text { set up or execute the function in different } \\
\text { way. } \\
\text { No timing for keystrokes. } \\
\text { When live events and no interactive and } \\
\text { synchronized media are shown, timing is } \\
\text { critical. } \\
\text { Must be provided enough time to read and } \\
\text { use the content }\end{array}$ \\
\hline \multicolumn{2}{|l|}{ 21. Image } \\
\hline Reference & Guideline \\
\hline $\begin{array}{l}\text { B6.1 } \\
\text { B6.2 } \\
\text { B11.2 } \\
\text { A3.3.1 } \\
\text { W1.1 } \\
\text { W1.1.1 } \\
\text { W1.4.5 } \\
\text { W1.4.9 }\end{array}$ & $\begin{array}{l}\text { When images are included: } \\
\bullet \text { Provide alternative text } \\
\text { - Decorative images must be hided when } \\
\text { assistive technology is used. } \\
\text { - Images must be distinguished when they } \\
\text { have an important function. } \\
\text { About images of text: } \\
\text { - They must be just decorative. } \\
\text { - Text showed in images must be avoided. } \\
\text { - They are used just if they convey } \\
\text { information. } \\
\text { - They can be customized by user. }\end{array}$ \\
\hline
\end{tabular}

Table 1 Unified mobile accessibility guidelines Source: own elaboration

The Table 1 shows the unified guidelines which can be easily read by developers and/or designers in order to increase or implement the mobile accessibility on apps.

\section{Conclusion}

There are a lot of guidelines related to web accessibility, some of them have been adapted to the mobile environment but the definition of mobile includes a wide range of devices, it means that smart glasses, smartphones, smartwatches, wearables, among others are considered mobile devices.

Even though there are sets of mobile accessibility guidelines, based on web accessibility guidelines, we consider that is mandatory to develop a specific standard about mobile accessibility in order to provide specific recommendations to implement or increase the accessibility on apps. This work of unification is a previous step to develop a specific mobile accessibility standard.

The set of guidelines unified shown has two purposes, first they can contribute to support the user (designer and/or programmer) to implement or increase the extent of accessibility when a mobile app is developed, and second, they are a preamble to standardize the mobile accessibility guidelines, this as a consequence of in the current days there is not an specific standard about mobile accessibility guidelines.

It is important to say that at the present time, the WCAG 2.0 are in process of standardization, however, these guidelines are focused on web accessibility and include recommendations oriented to the content shown on mobile devices such as tablets, smartphones, smartwatches, smart tv, among others. We consider that the mobile device term is of a very wide scope, so it is recommended, as a future work, to develop a specific accessibility guidelines for each of the mentioned devices.

\section{References}

Anderson P. and Perrin A. (2017). Tech adoption climbs among older adults. Retrieved June 5, 2019, from http://www.pewinternet.org/wpcontent/uploads/sites/9/2017/05/PI_2017.05.17 _Older-Americans-Tech_FINAL.pdf

Android (n. d.). Accessibility. Retrieved September 19, 2019, from https://material.io/design/usability/accessibility. html\# guidelines (UMAG). Journal of Technological Prototypes. 2020 
Android (n. d.). Imaginación sin límites. Retrieved September 7, 2019, from https://www.android.com/intl/es-419_mx/

BBC (2017a). Principles. Retrieved August 23, 2019, from

BBC (2017b). Mobile accessibility guidelines. Retrieved August 9, 2019, from https://www.bbc.co.uk/guidelines/futuremedia/a ccessibility/mobile

BBC (2019). What do I need to know about the $B B C$ ?. Retrieved September 10, 2019, from https://www.bbc.com/academy-guides/what-doi-need-to-know-about-the-bbc

https://www.bbc.co.uk/guidelines/futuremedia/a ccessibility/mobile/principles

ISO (2018). Ergonomics of human-system interaction - Part 11: Usability: Definitions and concepts. Retrieved October 6, 2019, from https://www.iso.org/obp/ui/\#iso:std:iso:9241:11:ed-2:v1:en

Lieberman, M. (2018). Technology Can Address Digital Accessibility. Retrieved December 2, 2019, from https://www.insidehighered.com/ digitallearning/article/2018/05/02/technology-canhelp-address-accessibility-challenges-many-say

López, N. and González, B. Análisis de las directivas de diseño para la accesibilidad móvil. Retrieved March 5, 2020, from http://revistatd.azc.uam.mx/index.php/rtd/articl e/view/63

Mariño, S. I., and Pagnoni, V. (2020). Accesibilidad Web en Dispositivos móviles. Evaluación de un portal educativo de alcance nacional. Retrieved February 15, 2020, from https://dialnet.unirioja.es/servlet/articulo?codig $\mathrm{o}=7250808$

Microsoft (n. d.). What's a Universal Windows Platform (UWP) app. Retrieved August 20, 2019, from https://docs.microsoft.com/enus/windows/uwp/get-started/universalapplication-platform-guide

W3C (2008). Web Content Accessibility Guidelines (WCAG) 2.0. Retrieved August 2, 2019, from https://www.w3.org/TR/WCAG20/
W3C (2017). Diverse abilities and barriers. Retrieved July 17, 2019, from https://www.w3.org/WAI/people-useweb/abilities-barriers/\#diversity 